\title{
Simple Analysis on the Reform and Research on Talent Cultivations of Dance Performance Major (sports dancing direction) in Universities in Shandong Province
}

\author{
Qin Fei, Qi Daobao* \\ Zaozhuang University \\ Zaozhuang, China
}

\begin{abstract}
With the arrival of the new era, people's demand for dance culture and art is constantly increasing. On the purpose of serving the development of local economic and promoting the construction of spiritual civilization, this paper analyzes the study situation, discusses the market demand and current situation of talent training, and hopes to improve the comprehensive quality and practical ability of students as well as enable them to engage in teaching, performing, choreographing and other work, so as to cultivate comprehensive and applied talents of dancing in line with the spirit of the new era and modern teaching concept.
\end{abstract}

Keywords-Reform on talent cultivation; dance performance major (sports dancing direction) in colleges in Shandong province; research; curriculum

\section{INTRODUCTION}

In recent years, due to the rising momentum of art exam fever in China, dance performance major (sports dancing direction) is also popular among students and parents. Therefore, some universities in Shandong province have offered this major. Through investigation, totally 9 universities in Shandong province offering this major, which are Shandong Sport University, Shandong Normal University, Qufu Normal University, Linyi University, Zaozhuang University, Binzhou University, Taishan University, Weifang University and Heze University. In this new era, how to meet the needs of the local market, universities in Shandong province should cultivate what kind of dance performance major (sports dancing) talent and what kind of talent training mode should be established become our current problem that cannot be ignored.

\section{THE PRESENT SITUATION OF TALENT TRAINING OF} DANCE PERFORMANCE MAJOR (SPORTS DANCING DIRECTION) IN UNIVERSITIES IN SHANDONG PROVINCE

\section{A. Basic information of students}

Shandong province, as a national arts exam province, has a good market and source of students. Universities across the country are rushing to set up test centers in Shandong province, which also promotes the strong development of the market. Due to the special geographical location of Shandong province and the congenital conditions of people, students in this province are much taller with good image and temperament, which provides a good foundation for learning sports dancing. However, most students choose the shortcut of arts exam in order to enter higher education, so they are basically not be trained since childhood and most of them start to learn sports dancing in senior one or even the first semester of senior three. For the learning time is short, the only dances they have been trained are rumba, cha-cha dance, waltz and tango for the testing requirements. As a result, they learn fewer kinds of dances and the technical foundation is relative weak. In addition, since they are transferred from cultural class students, their physical quality (softness, strength, burst and endurance, etc.) is also relatively poor.

In Shandong province, the overall entrance performance of students majoring in sports dancing is low and the imbalance exists in the ratio of male to female students. After entering school, fewer students have participated in sports dancing competitions and received after-school training.

\section{B. Teaching staff}

At present, there is a gender imbalance in the number of sports dancing teachers in universities in Shandong province. The number of male teachers is larger than the number of female teachers and mainly between 25 and 40 years old. There are too many lecturers and assistants, without professor, doctor or graduate student, so that they may lack of rich teaching experience. The teachers are mostly teaching technical and put little time in scientific research, so that the scientific research output and the quality are not high. And it reflects weak scientific research consciousness of the sports dancing teachers of Shandong province and affects the overall scientific research level. Due to their limited comprehensive level, some teachers only pay attention to special technical ability of their students and despise or neglect the cultivation of sports dancing theory, research and innovation ability of them. The learning, training and competitions of teachers are mainly at their own expense. Moreover, the insufficient funds for on-the-job training will affect teachers' willingness to participate in training to some extent, thus affecting the improvement of teachers' quality level. And improper rewards will easily lead to negative working 
attitude, which is not conducive to the professional development for teachers. From the view of the current development level of sports dancing in university in Shandong province, the overall quality of college sports dancing teachers cannot meet the needs of their discipline construction and development[1].

\section{Curriculum setting}

After investigating the talent training program and outline of various universities as well as comparing and analyzing the teaching hours and credits, the teaching hours and credits of various universities in Shandong province are quite different from each other in the teaching plans of the talent training program, besides, the teaching hours and credits of some courses are not in direct proportion. For the same course, the class hours and credits vary greatly in the teaching plans of the talent training programs of different universities. Some universities do not pay attention to subject education courses and accounts for less class hours and credits, which is not conducive for students to master the basic theoretical knowledge; some universities take many class hours and credits on subject education courses and it is obviously considering that the theory is much more important than practice and; in some universities, the proportion of class hours and credits of elective courses is obviously higher than that of compulsory courses, which adds unnecessary burden to students and makes them not pay attention to compulsory courses.

Some universities pay more attention to the training of theoretical knowledge but neglect the training of special technical skills. On the contrary, some universities pay more attention to the training of special technical skills and neglect the training of theoretical knowledge. And some may neglect the education of public courses.

The teaching plans in the talent training program of various universities are different and do not reflect the clear direction of talent training. The imbalance of teaching plan is not good for cultivating all-round talents. Moreover, the talent training program of various universities have their own characteristics, some have slightly simple curriculum plan structure and unclear classification structure, for example, same type of courses is divided into different types of courses, which cannot serve as an effective reference for teachers of various universities.

\section{Resource allocation}

The young sports dancing teachers in universities in Shandong province are all prefer technology than theory, none of them are engaged in the theoretical research of sports dancing. Since the teachers prefer technology, they would like to teach technology during the course and ignore the importance of the combination of theory and practice. In universities, there is no unified teaching material for sports dancing and the teaching methods are single as well as unreasonably use of modern information technology, which are the teaching malpractice of sports dancing teachers in universities. During the overall planning of teaching plan, teachers teach the students with their own competition, education experience and individual preference and it would be not helpful for the cultivation for the students.
The venues of universities in Shandong province are not perfect, especially the venues and facilities for sports dancing, which are slightly inferior to those of universities outside the province and far from the ideal venues of most students. The inattention of the superior leaders, the insufficient allocation of the management department as well as unclear planning and construction of the venue facilities for sports dancing are the important reasons leading to the imperfect venue, which makes the venue fund unable to be guaranteed or in shortage. A fixed training and learning venue and complete overall equipment are the basic condition for students in learning sports dancing. One of the most advocated teaching methods includes the use of modern multimedia equipment. In addition to the limited classroom, the multimedia makes full use of teaching methods to combine theory with practice after class, so that students can learning deeper, self-practice, grinding and improve the further understanding of what is learned in class. There are also many students who love sports dancing and they want to improve themselves through training and competitions, but the reality is not allowed, for most universities do not open the venues to students after class.

\section{THE DEMAND OF SOCIAL MARKET FOR DANCE} PERFORMANCE MAJOR (SPORTS DANCING DIRECTION)

With the arrival of new era, people's demand for dance culture and art is constantly increasing as well as the demand for the performance talent at all level. Therefore, from the perspective of supply and demand, when the supply is less than the demand, the professional dance talents will work and serve the society at a high price and vice versa. So, the market equilibrium is formed by the interaction between supply and demand. According to the investigation, single talent training mode for dance performance major (sports dancing direction) of universities in Shandong province and the professional knowledge (basic skills and techniques) for dance performance (sports dancing) make it difficult to promote the scale and level as well as lead to insufficient motivation and conditions for other direction. Under the requirements of the market economy, in facing of the students or the fitness members, the talents should be able to teach basic technology and professional knowledge; in facing of the masses, they should be able to create good works and; in facing of social groups, cultural and sports activities, they should be able to understand the management, overall arrangement and so on, all of that requires the dance performance talents (sports dancing) to be a creative talent with comprehensive knowledge.

IV. REFORM AND RESEARCH ON TALENT CULTIVATIONS OF DANCE PERFORMANCE MAJOR (SPORTS DANCING DIRECTION) IN UNIVERSITIES IN SHANDONG PROVINCE

Based on the current situation of students and the relationship between the needs of the social market, active exploration for the talent training of dance performance major (sports dancing) in universities in Shandong province will be made to make it more standardized and scientific.

\section{A. Improvement of students' comprehensive ability}

Students of this major should strengthen their study of sports dancing technology, skills and theoretical knowledge to lay a good foundation for the social market that needs technical 
talents. With the large demand for the dancers who are capable with choreography, performance and other capabilities from the social groups, enterprises and training institutions, comprehensive quality of students of this major should be strengthened to meet the needs of various talents.

In the long term of teaching practice experience, the cultivation of practical ability for students should be strengthened in the talents training program for dance performance major (sports dancing) in universities in Shandong province and on the basis of service to the local regional economic development, proper reform for the cultivation mode for talents of dance performance major (sports dancing direction) in universities in Shandong province needs to be done. The specific measures include: (1) the art practice: tour performances, dance, and social investigation, etc. (2) the teaching practice: analysis on the dance works (3) the graduation practice: combination of campus and off-campus internship (4) the graduation design: dance creation with social hot issues and (5) the performance: perform the basic skills learned in the past 4 years and the ability to create and write performances[2].

\section{B. Strengthen the construction of teaching staff}

In the competition among universities of the same special subject, excellent teaching staffs is an important factor. The annual basic skills contest of teacher between universities should add the sports dancing project and keep the characteristics and specialist of the project. Dancing of two people (one male and one female) is the characteristic of sports dancing, male teacher teaches male steps and female teacher teaches female steps so that make students clear with the main points of every actions and the expressive force and improve the teaching quality and teaching effect in a good teaching atmosphere. Sports dancing is the combination of sport and art, during the teaching progress, teachers should possess not only the system theory knowledge, but also professional and technical skills, which requires highly attention should be paid on the theoretical knowledge and comprehensive qualities such as special technical skills of the teachers while hiring teachers. The development and the introduction of the teacher with both theoretical knowledge and special technical skills reflect the optimizing for the structure of teaching staffs in Shandong province. To improve the comprehensive quality of teacher and strengthen the construction of teaching staff and improve the reward system for teacher. Measures should be taken, such as provide more learning opportunities, trainings, competitions and exchanges after entering the post, encourage teachers to improve their comprehensive quality and actively participate in the research of education and teaching after completing the prescribed teaching objectives and tasks, to promote the vigorous development of sports dancing in Shandong province [3].

\section{Improvement of education and teaching resources}

In order to improve the venues and facilities of each university, it is of great importance to change the concept of superior leaders on sports dancing, to ensure the financial input on venues and facilities for sports dancing. Flexible use of multimedia teaching methods and improve the utilization rate of modern teaching methods, which means the use of PPT and videos in the teaching of sports dancing can improve the learning atmosphere, active their thinking and promote their interest in learning. The use of multimedia teaching enables students to conduct self-evaluation by means of video, find their shortcomings and develop a good habit of independent learning as well as self-evaluation, thus improve the learning effect and training effect of students. The improvement of venues and facilities for sports dancing in universities, optimizing of teaching environment and opening of the venues are good insurance for which can stimulate their interest in learning.

\section{Optimization of teaching program and evaluation method}

The teaching program must conform to the talent cultivation plan. The teaching program of each university should be in line with the cultivation objectives of the talent cultivation plan, meet the needs of modern society for comprehensive and applied talents of dancing, pay attention to the distribution of teaching plans, adjust teaching contents, methods and means and teachers should flexibly use of teaching methods while teaching. Every universities should be in strict accordance with the revision of the program of the talent cultivation plan. While teaching, teachers should combine theory and practice according the teaching plan and scheme of teaching program. In the progress of assessment and evaluation, teachers and students should pay attention to the mutual evaluation, teachers may get teaching feedback by means of teaching evaluation methods such as the opinion of the teaching content, methods and means from students and then conduct summary and adjustment to improve the teaching quality in the final.

\section{CONCLUSION}

Universities in Shandong province should highly value the construction of teaching staff, strengthen the overall quality of teachers, clarify the direction of talent cultivation, adjust the setting of curriculum content, improve education and teaching resources, stimulate the interest of students while teaching, improve the learning effect and finally promote the vigorous development of sports dancing in Shandong province.

\section{REFERENCES}

[1] Li Jing. Investigation and Research on the Current Situation of Talen Cultivation of Art Majors (sports dancing) in Universities in Shandong Province. Qufu Normal University, 2017. (In Chinese)

[2] Tian Liping. Analysis on the Training Mode of Dance Talents [J]. Grand Stage Publishing House, 2010. (In Chinese)

[3] Yan Jie. Reform of Training Mode for Dance Professionals in Universities [J]. Contemporary Art Observation, 2014. (In Chinese)

[4] Long Mengpei, Xu Erchong. Introduction on Dancing Art [M]. Shanghai: Shanghai Music Publishing House. 2010. (In Chinese)

[5] Liu Yayun. Research on the Training Mode of Competitive Sports Talents in China during the Social Transformation. Hunan Normal University, 2011. (In Chinese)

[6] Wang Xiaohui. Research on Personalized Talent Training Mode of First-class Universities [D]. Huazhong Normal University, 2014. (In Chinese) 